\title{
Friction Properties of Cluster Diamond/Glassy Carbon Composites
}

\author{
Michita $\mathrm{HOKAO}^{\dagger}$ and Seiichiro HIRONAKA \\ Department of Inorganic Materials, Faculty of Engineering, Tokyo Institute of Technology, 2-12-1, O-okayama, Meguro-ku, Tokyo $152-8552$
}

\author{
クラスターダイヤモンド/ガラス状炭素複合材料の摩擦特性 \\ 外尾道太 \\ 東京工業大学工学部無機材料工学科, 152-8552 東京都目黒区大岡山 2-12-1
}

\begin{abstract}
This paper describes the friction properties of cluster diamond/glassy carbon (CD/GC) composites and graphite cluster diamond/glassy carbon (GCD/GC) composites as self-lubricating materials. CDs and GCDs in the shape of superfine particles are intended as solid lubricants. Friction tests were performed on several friction surfaces by varying sliding velocity and load. Testing was carried out in three friction environments (i.e., ambient air, mineral oil and distilled water). The results of these tests revealed that the friction behavior of $\mathrm{CD} / \mathrm{GC}$ and GCD/GC composites is mainly influenced by both load and CD (or GCD) content in the composites. Their friction coefficients decreased as the load decreased under low load and low sliding velocity in ambient air. In addition, little influence of the friction environments was observed in the friction properties. Consequently, CD/GC and GCD/GC composites are promising as self-lubricating materials, particularly under low-load conditions.

[Received April 24, 2000; Accepted July 19, 2000]
\end{abstract}

Key-words : Cluster diamond, Graphite cluster diamond, Glassy carbon, Friction, Self-lubricating

\section{Introduction}

Self-lubricating materials have been increasing in importance in tribological systems, because they have the advantage of operating over a wide range of friction environments and having permanent lubrication unless they are worn out. ${ }^{1)}$ As typical self-lubricating materials, composite materials consist of a supporting matrix and dispersed lubricating species. Various polymeric and ceramic materials are used for the matrix and lubricating species are usually selected from lubricating oils or solid lubricants such as soft metals, polytetrafluoroethylene (PTFE), molybdenum disulfide $\left(\mathrm{MoS}_{2}\right)$ and graphite.

Glassy carbon (GC) is a family of hard carbon and possesses various excellent properties such as low density, high hardness, corrosion resistance, wear resistance ${ }^{2)}$ and low friction coefficient. ${ }^{3)}$ These properties indicate the potential of GC for tribological use in a variety of friction environments such as ambient air, water and corrosive environments. However, friction studies of GC have been rarely reported. From this viewpoint, we previously reported the friction and wear properties of graphite/glassy carbon (G/ GC) composites as a new self-lubricating material. ${ }^{4)}$ It was shown that the friction and wear properties of GC were improved by composing it with graphite; in addition, the GC matrix composite materials were promising as self-lubricating materials.

This study investigates the friction properties of cluster diamond/glassy carbon (CD/GC) composites and graphite cluster diamond/glassy carbon (GCD/GC) composites as a GC matrix self-lubricating composite. CDs and GCDs consist of superfine particles of diamond single crystals, and GCDs contain the graphite structure. They are produced by the detonation of trinitrotoluene (TNT) explosives. CDs and GCDs have been of interest as solid lubricants or abrasives in recent years. ${ }^{5)-7)}$ There are, however, only a few

\footnotetext{
Now with Basic Technology Research and Development Center, NSK Ltd., 1-5-50, Kugenumashinmei, Fujisawa-shi, Kanagawa $251-8501$

現在:日本精工 (株)基盤技術研究所，251-8501 神奈川県藤沢 市鵜沼神明 1-5-50
}

studies on these materials as solid lubricants. ${ }^{5), 6)}$ Therefore, this study investigated the potential of these new selflubricating composites and the effect of CDs and GCDs as solid lubricants. The friction tests were conducted under various test conditions for three kinds of pins (i.e., steel, alumina, tungsten carbide), several sliding velocities and normal loads, and three friction environments (i.e., ambient air, low viscosity mineral oil and distilled water). The friction mechanism of the composites was examined by observations of the morphology of worn surfaces by scanning electron microscope (SEM).

\section{Experimental}

\subsection{Samples}

GC matrix composite materials were prepared by pyrolysis of a mixture of GC as a raw material and a variety of fine particles shown in Table 1 at $1400^{\circ} \mathrm{C}$ under nitrogen atmosphere after a precarbonization process. GC as a raw material was a mixture of furan resin, furfural and furfryl alcohol. Fine particles are commercially available (Tokyo Diamond Tools Mfg. Co., Ltd.). For CD/GC composites and GCD/GC composites, composites containing different particle contents (5, 10 and 20 mass\%) were prepared. However, other GC matrix composites containing graphite, hexagonal boron nitride and silicon carbide possessed constant particle contents (24, 20 and 13 mass \%), respectively. The particle content of these composites was decided by referring to our previous study of $\mathrm{G} / \mathrm{GC}$ composites. ${ }^{4)}$ Typical properties of $\mathrm{CD} / \mathrm{GC}$ and $\mathrm{GCD} / \mathrm{GC}$ composites are shown in Table 2. The X-ray diffraction patterns of GC, $\mathrm{CD} / \mathrm{GC}$ composites (CD20) and GCD/GC composites (GCD20) exhibited broad peaks due to the graphite structure, which was confirmed in GC (Fig. 1). A weak diamond (111) diffraction peak was recognized in $\mathrm{CD} / \mathrm{GC}$ and $\mathrm{GCD} /$ GC composites. Therefore, this confirmed the existence of $\mathrm{CD}$ particles in prepared $\mathrm{CD} / \mathrm{GC}$ composites. All GC matrix composites were formed in disks with an approximate size of outer diameter $50 \mathrm{~mm}$, inner diameter $10 \mathrm{~mm}$ and thickness $0.5 \mathrm{~mm}$. Although insufficient thickness prevented us from polishing the disk surface, surface roughness of those samples corresponded to $10^{-7} \mathrm{~m}$. In the friction tests, CD/ 
Table 1. Nature of Mixed Fine Particles

\begin{tabular}{|c|c|c|c|}
\hline Sample & Composition & $\begin{array}{c}\text { Average particle } \\
\text { size } / 10^{-6} \mathrm{~m}\end{array}$ & $\begin{array}{c}\text { Particle content } \\
\text { mass } \%\end{array}$ \\
\hline $\mathrm{CD} / \mathrm{GC}$ & Cluster diamond & 0.005 & $5,10,20$ \\
\hline $\mathrm{GCD} / \mathrm{GC}$ & $\begin{array}{c}\text { Graphite } \\
\text { cluster diamond }\end{array}$ & 0.02 & $5,10,20$ \\
\hline $\mathrm{G} / \mathrm{GC}$ & Graphite & 3 & 24 \\
\hline $\mathrm{hBN} / \mathrm{GC}$ & $\begin{array}{l}\text { Hexagonal } \\
\text { boron nitride }\end{array}$ & $5-7$ & 20 \\
\hline $\mathrm{SiC} / \mathrm{GC}$ & Silicon carbide & 2 & 13 \\
\hline
\end{tabular}

Table 2. Typical Properties of CD/GC and GCD/GC Composites

\begin{tabular}{cccc}
\hline Sample & $\begin{array}{c}\text { CD:GC } \\
\text { mass\% }\end{array}$ & $\begin{array}{c}\text { Density } \\
10^{3} \mathrm{~kg} \mathrm{~m}^{-3}\end{array}$ & $\begin{array}{c}\text { Vickers hardness } \\
\text { HV }\end{array}$ \\
\hline GC & $0: 100$ & 1.47 & 283 \\
CD5 & $5: 95$ & 1.51 & 192 \\
CD10 & $10: 90$ & 1.52 & 144 \\
CD20 & $20: 80$ & 1.53 & 121 \\
\hline \multicolumn{4}{c}{} \\
\hline Sample & GCD:GC & Density & Vickers hardness \\
& mass\% & $10^{3} \mathrm{~kg} \mathrm{~m}^{-3}$ & HV \\
\hline GCD5 & $5: 95$ & 1.51 & 217 \\
GCD10 & $10: 90$ & 1.52 & 317 \\
GCD20 & $20: 80$ & 1.50 & 283 \\
\hline
\end{tabular}

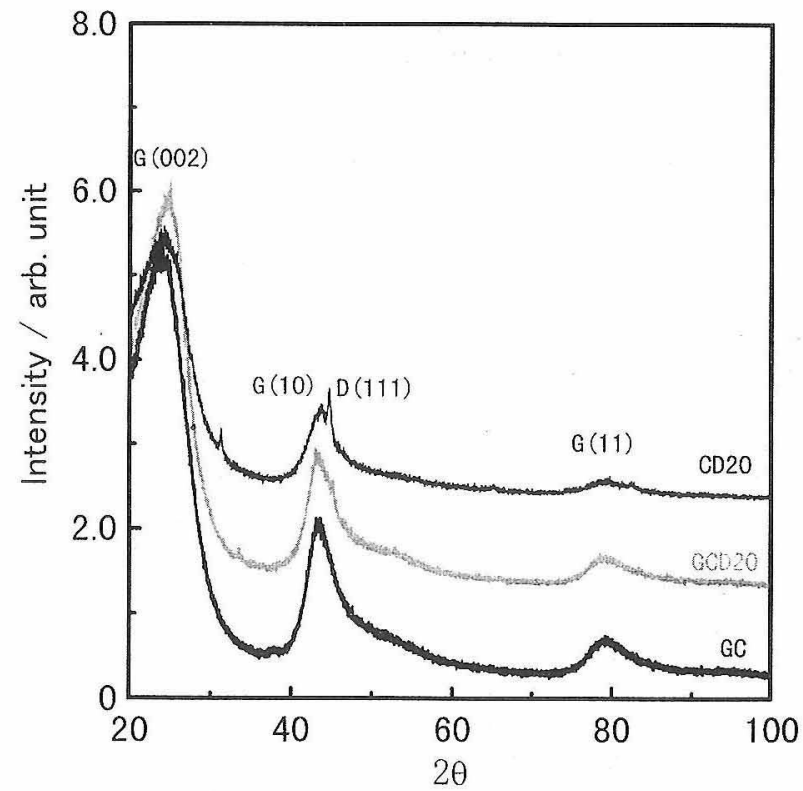

Fig. 1. X-ray diffraction patterns. The symbols " $G$ " and "D" represent graphite and diamond.

GC or GCD/GC composites were slid against SUJ2 steel (JIS G 4805), alumina and tungsten carbide pins. Tungsten carbide specimens contained 6 mass\% Co. These specimens were ground smooth and shaped hemispherically. The forms of these pins are listed in Table 3.
Table 3. Forms of Pins

\begin{tabular}{ccc}
\hline Sample & $\begin{array}{c}\text { Surface roughness } \\
\mathrm{Ra} / 10^{-9} \mathrm{~m}\end{array}$ & $\begin{array}{c}\text { Curvature radius } \\
10^{-3} \mathrm{~m}\end{array}$ \\
\hline SUJ2 steel & 2 & 2.4 \\
Alumina & 41 & 2.9 \\
Tungsten carbide & 8 & 0.7 \\
\hline
\end{tabular}

\subsection{Friction tests}

This experiment was conducted in nonlubricating (ambient air) and lubricating environments (water and oil). As for the friction tests under the nonlubricating conditions, two friction apparatuses, a pin/disk type and a Bowden-Leben type, were used. A sketch of the pin/disk apparatus geometry is shown in Fig. 2. This apparatus measured the friction force occurring between a rotating disk and a static pin at a constant sliding velocity $(0.1 \mathrm{~m} / \mathrm{s})$ and various loads $(2.0,9.8$ and $19.6 \mathrm{~N})$. A variety of GC matrix composites were used for disk samples and steel and alumina specimens for pin samples. Figure 3 shows a sketch of the geometry of Bowden-Leben apparatus. The disk moved in a constant direction against the static pin in this apparatus. $\mathrm{CD} / \mathrm{GC}$ or GCD/GC composites and tungsten carbide were used as disk and pin specimens, respectively. The Bowden-Leben apparatus was specifically used for friction tests under conditions of low sliding velocities $\left(1.7 \times 10^{-3} \mathrm{~m} / \mathrm{s}\right.$, $8.3 \times 10^{-3} \mathrm{~m} / \mathrm{s}$ and $\left.17 \times 10^{-3} \mathrm{~m} / \mathrm{s}\right)$ and low loads $(0.39 \mathrm{~N}$, $0.77 \mathrm{~N}$ and $1.5 \mathrm{~N}$ ). These friction tests were conducted at room temperature in ambient air. As for the friction experiments under lubricating conditions, distilled water and low

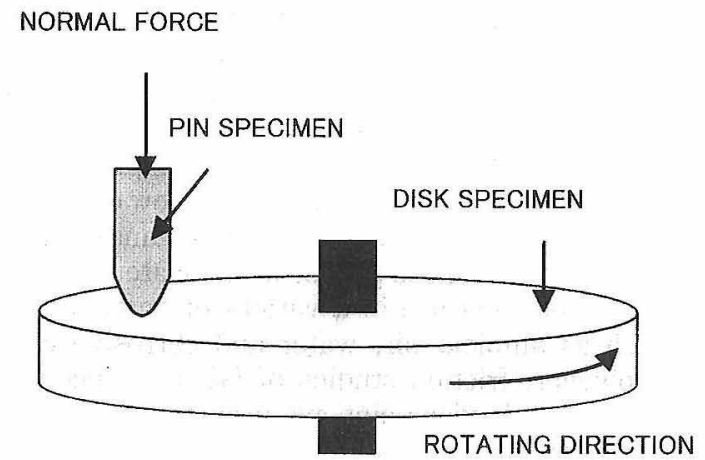

Fig. 2. A sketch of the geometry of the pin/disk friction apparatus.

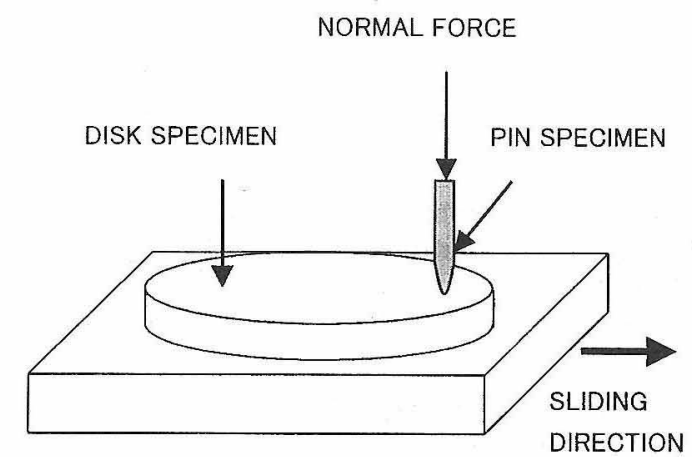

Fig. 3. A sketch of the geometry of the Bowden-Leben friction apparatus. 
viscosity mineral oil were applied as lubricants. The pin/ disk apparatus was used for these tests under constant conditions of $0.1 \mathrm{~m} / \mathrm{s}, 2.0 \mathrm{~N}$ and room temperature. The friction interface was completely immersed in lubricants.

Experiments were conducted at least twice under each set of conditions. The average friction coefficient over the entire sliding distance was adopted as the mean friction coefficient. After the friction tests, the morphology of the worn track in the disks was observed by SEM.

\section{Results and discussion}

\subsection{Friction coefficient}

Figure 4 shows the mean friction coefficient of the GC matrix composites as shown in Table 1 . When the composites and GC were slid against steel specimens, the friction coefficient was approximately half of that against alumina specimens. Among the composites, those containing CD, GCD and graphite particles showed lower friction coefficients than GC, which was in contrast with the composites containing $\mathrm{hBN}$ and $\mathrm{SiC}$. This result indicates that these solid lubricants are effective at reducing the friction coefficient of GC by composition with it. In particular, CD/ GC showed the lowest friction coefficient among these five composites. The mean friction coefficients of $\mathrm{CD} / \mathrm{GC}$ slid against steel and alumina specimens were about 0.05 and 0.08 , respectively, under these test conditions. In general, these very low friction coefficients could hardly be obtained in nonlubricating environments.

The typical variation of the friction coefficient with sliding distance for GC, CD/GC composites (CD20) and GCD/GC composites (GCD20) is shown in Fig. 5. When these samples were slid against steel specimens and alumina specimens, their friction coefficients were almost constant throughout the duration of the test. As compared with GC, CD20 and GCD20 showed more stable friction behavior with less deflection in the friction coefficient.

The dependence of the mean friction coefficient of $\mathrm{CD} /$ $\mathrm{GC}$ composites on the $\mathrm{CD}$ content under various loads is shown in Fig. 6. In this load range, the correlation between $\mathrm{CD}$ content and the mean friction coefficient was not clear, and the mean friction coefficient was not fixed by the load in either pin/disk system. It was, however, clear that the friction coefficient of $\mathrm{CD} / \mathrm{GC}$ composites sliding against steel specimens was lower than that against alumina specimens, independent of the $\mathrm{CD}$ content and the applied load. Besides, $\mathrm{CD} / \mathrm{GC}$ composites containing above 10 mass\% $\mathrm{CD}$

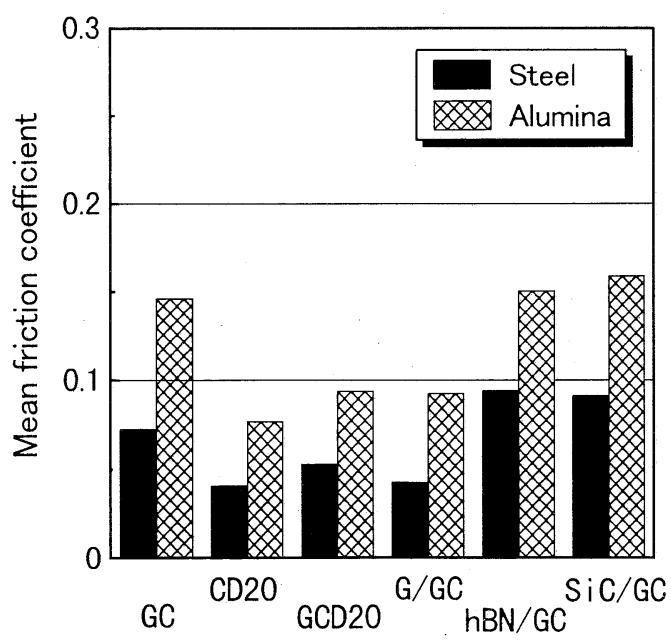

Fig. 4. Mean friction coefficient of GC matrix composites sliding against steel and alumina specimens at $0.1 \mathrm{~m} / \mathrm{s}$ and $2.0 \mathrm{~N}$.
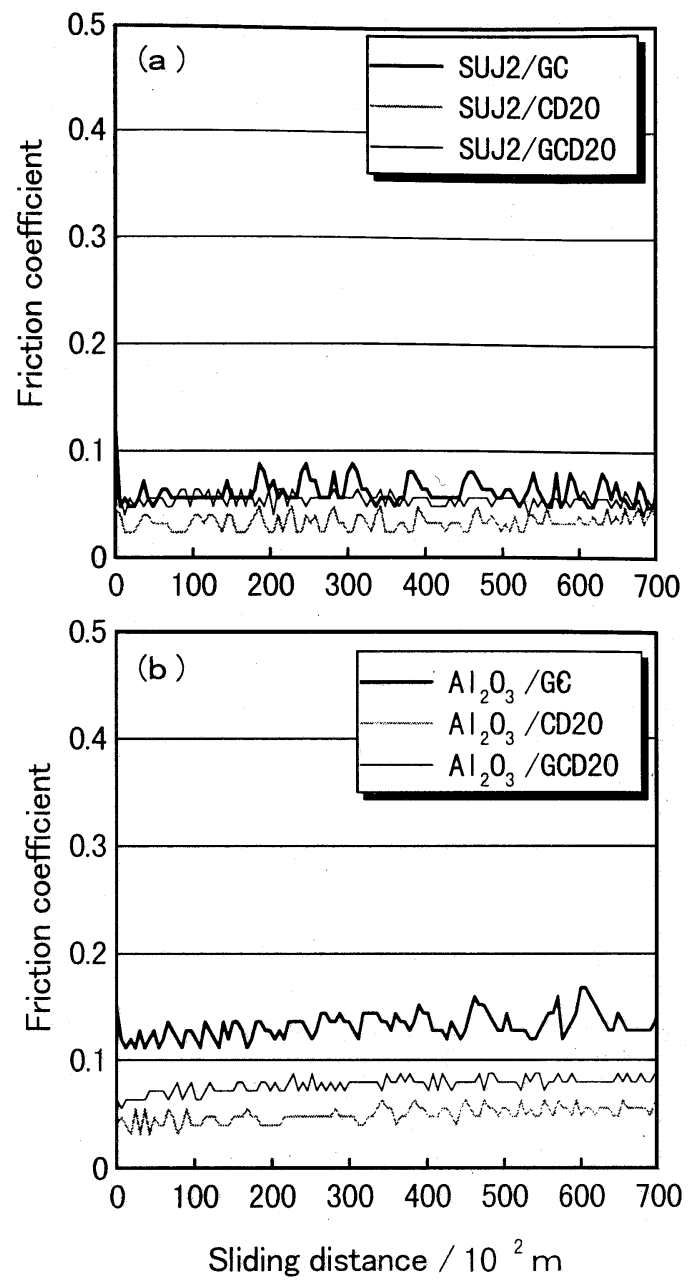

Fig. 5. Variation of the friction coefficient against sliding distance at $0.1 \mathrm{~m} / \mathrm{s}$ and $2.0 \mathrm{~N}$, (a) slid against steel, (b) slid against alumina.

showed lower mean friction coefficients than GC under each load. The effect of the composition of $\mathrm{CD}$ particles on the friction coefficient was obtained clearly under lower loads. This typical example was obtained when the composites were slid against alumina specimens under the load of $2.0 \mathrm{~N}$. These results indicate the significance of the contact pressure at the friction area to the friction properties of $\mathrm{CD} / \mathrm{GC}$ composites.

To examine the detailed influence of the load and the sliding velocity on the friction coefficient, friction tests at low normal load $(0.39,0.77$ and $1.5 \mathrm{~N})$ and low sliding velocity $\left(1.7 \times 10^{-3}, 8.3 \times 10^{-3}\right.$ and $\left.17 \times 10^{-3} \mathrm{~m} / \mathrm{s}\right)$ were conducted. In these experiments, tungsten carbide specimens were used as the pins. Figure 7 shows the dependence of the mean friction coefficient on the CD content under low loads. The mean friction coefficient decreased as the CD content increased under either load. This tendency was different from the result under higher loads shown in Fig. 6 . The degree of decrease in the friction coefficient was larger with decreasing load. The variation of the mean friction coefficient with GCD content of GCD/GC composites is shown in. Fig. 8. The decrease of the mean friction coefficient as particle content increased was also observed in GCD/GC composites, although the degree of the reduction was smaller than that in $\mathrm{CD} / \mathrm{GC}$ composites. In addition, GCD/GC composites showed a slightly higher mean friction coefficient than $\mathrm{CD} / \mathrm{GC}$ composites. 

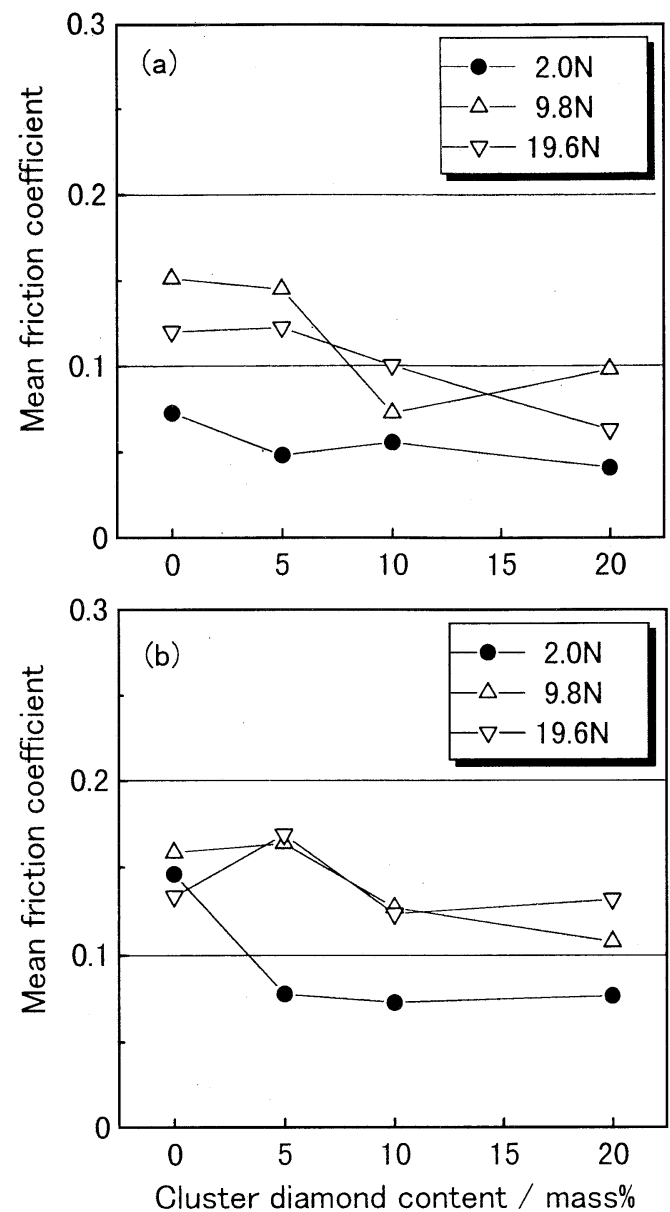

Fig. 6. Variation of the mean friction coefficient with CD content of $\mathrm{CD} / \mathrm{GC}$ composites at various loads and $0.1 \mathrm{~m} / \mathrm{s}$, (a) slid against steel, (b) slid against alumina.

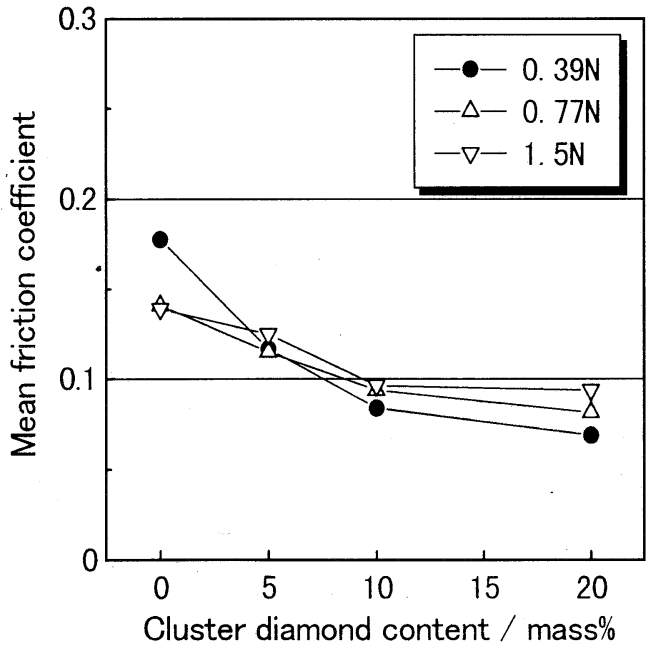

Fig. 7. Variation of the mean friction coefficient with cluster diamond content of $\mathrm{CD} / \mathrm{GC}$ composites sliding against tungsten carbide at various loads and $1.7 \times 10^{-3} \mathrm{~m} / \mathrm{s}$.

The dependence of sliding velocity on the mean friction coefficient of $\mathrm{CD} / \mathrm{GC}$ composites under low load $(0.39 \mathrm{~N})$ is shown in Fig. 9. The mean friction coefficient of the CD/GC composites had little influence on the sliding velocity under

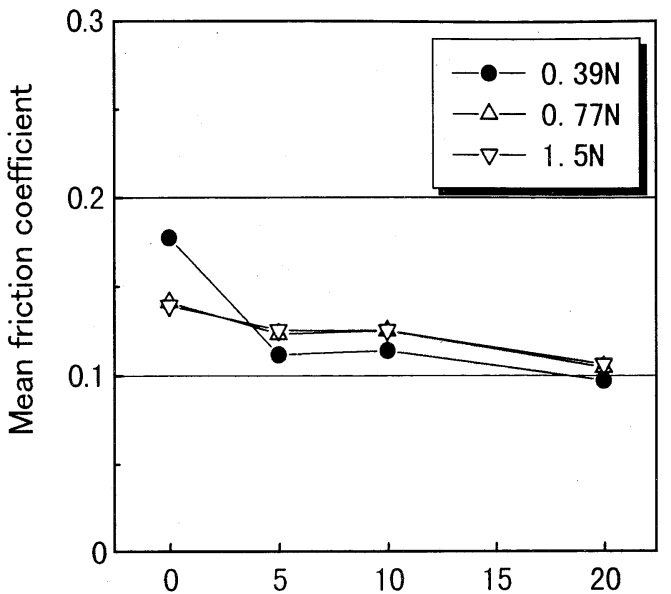

Graphite cluster diamond content / mass\%

Fig. 8. Variation of the mean friction coefficient with graphite cluster diamond content of GCD/GC composites sliding against tungsten carbide at various loads and $1.7 \times 10^{-3} \mathrm{~m} / \mathrm{s}$.

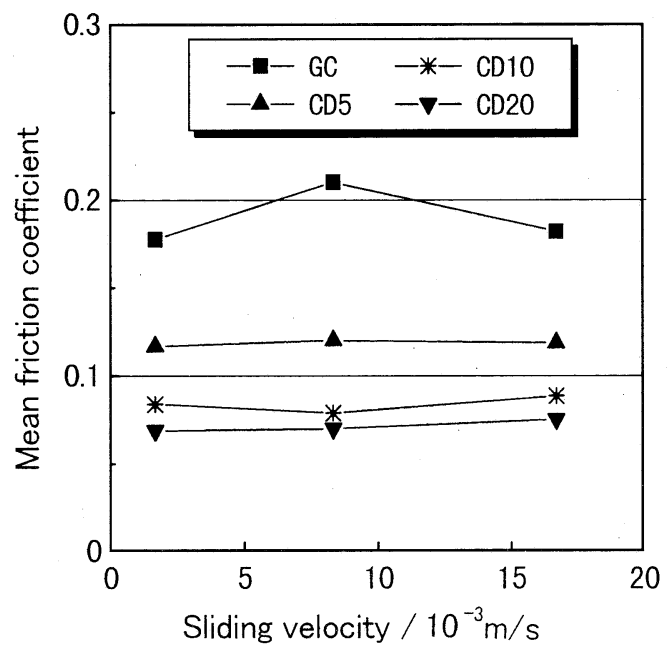

Fig. 9. Variation of the mean friction coefficient with sliding velocity of $\mathrm{CD} / \mathrm{GC}$ composites sliding against tungsten carbide at $0.39 \mathrm{~N}$.

these test conditions.

The reason for these results may indicate that $\mathrm{CD}$ or GCD particles existing at friction interface significantly influence friction properties of $\mathrm{CD} / \mathrm{GC}$ or GCD/GC composites under low loads. CD and GCD are considered to possess high hardness and chemical inertness, therefore these super fine particles may play an important role in solid lubricants by preventing the direct contact with the GC matrix, especially at low contact pressure.

The variation of the mean friction coefficient with the friction environments (i.e., air, mineral oil and distilled water) at $0.1 \mathrm{~m} / \mathrm{s}$ and $2.0 \mathrm{~N}$ is shown in Fig. 10. The mean friction coefficient of $\mathrm{CD} / \mathrm{GC}$ composites (CD20) and GCD/GC composites (GCD20) in each friction environment did not change greatly under these test conditions. With oil or water lubrication, the effect of CDs or GCDs on the mean friction coefficient of glassy carbon was not clear, in contrast to the nonlubricating condition.

\subsection{Morphological observations}

The morphology of the worn tracks of GC obtained under 

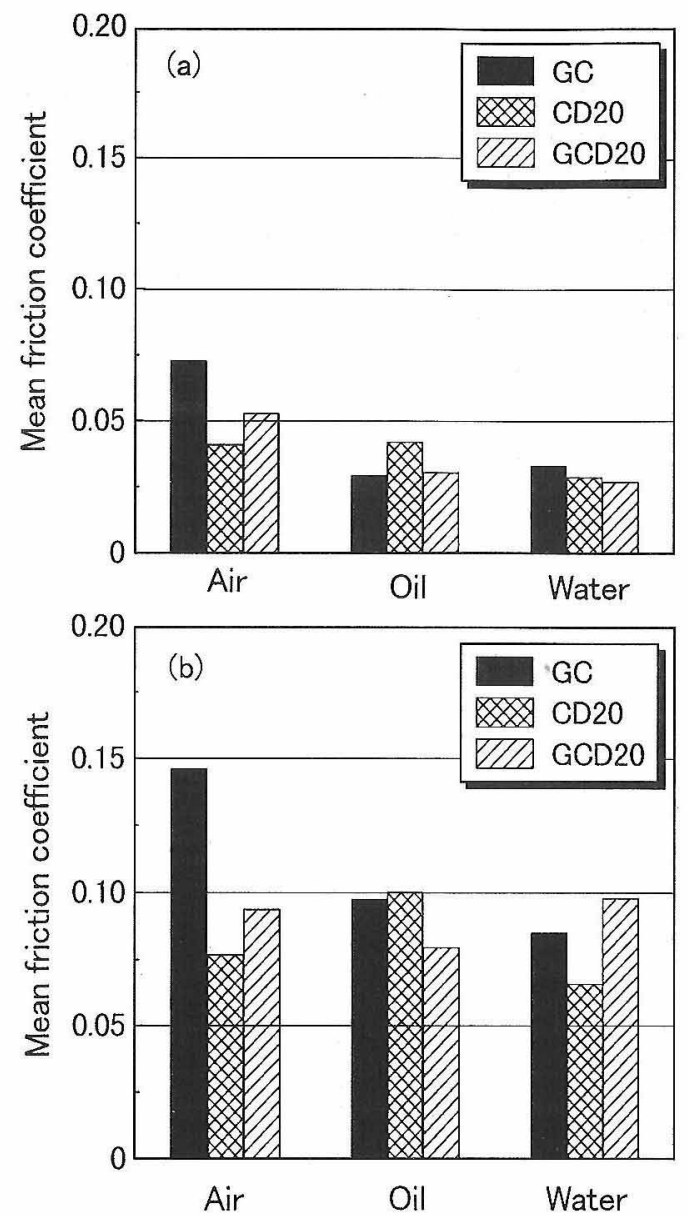

Fig. 10. Variation of the mean friction coefficient with the friction environment at $0.1 \mathrm{~m} / \mathrm{s}$ and $2.0 \mathrm{~N}$, (a) slid against steel, (b) slid against alumina.

a load of $9.8 \mathrm{~N}$ is shown in Fig. 11. Some small holes were seen at the center of the worn track of the GC sample slid against the alumina specimen (Fig. 11(a)). It seems that thin surface layers came off the friction interface. Repeated exfoliation of thin layers led to flaking and produced holes. It is likely that the flaking of the friction interface is caused by repeated stress-reverse effects leading to delamination, ${ }^{8)}$ because GC contains many minute, close pores. ${ }^{9), 10)}$ Therefore, it is suggested that delamination is one of the main friction and wear mechanisms of GC. The surface of the worn GC track in the steel/GC system (Fig. 11(b)) was very rough. The morphology of the worn area appeared to be similar to the flaking areas seen in the alumina/GC system. Therefore, it is also considered that one of the mechanisms of wear in this system was delamination. However, it is not clear what produced the morphological differences between the worn GC tracks slid against each pin. It may be that these morphologies were influenced by the difference in contact area due to the different surface roughness of each pin.

The worn surface of $\mathrm{CD} / \mathrm{GC}$ composites (CD20) obtained under a load of $9.8 \mathrm{~N}$ is shown in Fig. 12. There were many narrow grooves parallel to the sliding direction in the CD20 surface slid against alumina (Fig. 12(a)), and these traces of wear are hardly seen in GC (Fig. 11(a)). These grooves are considered to be the results of plowing the alumina specimen. The holes seen in the worn GC surface were hardly observed in the worn CD20 surface slid against alumina
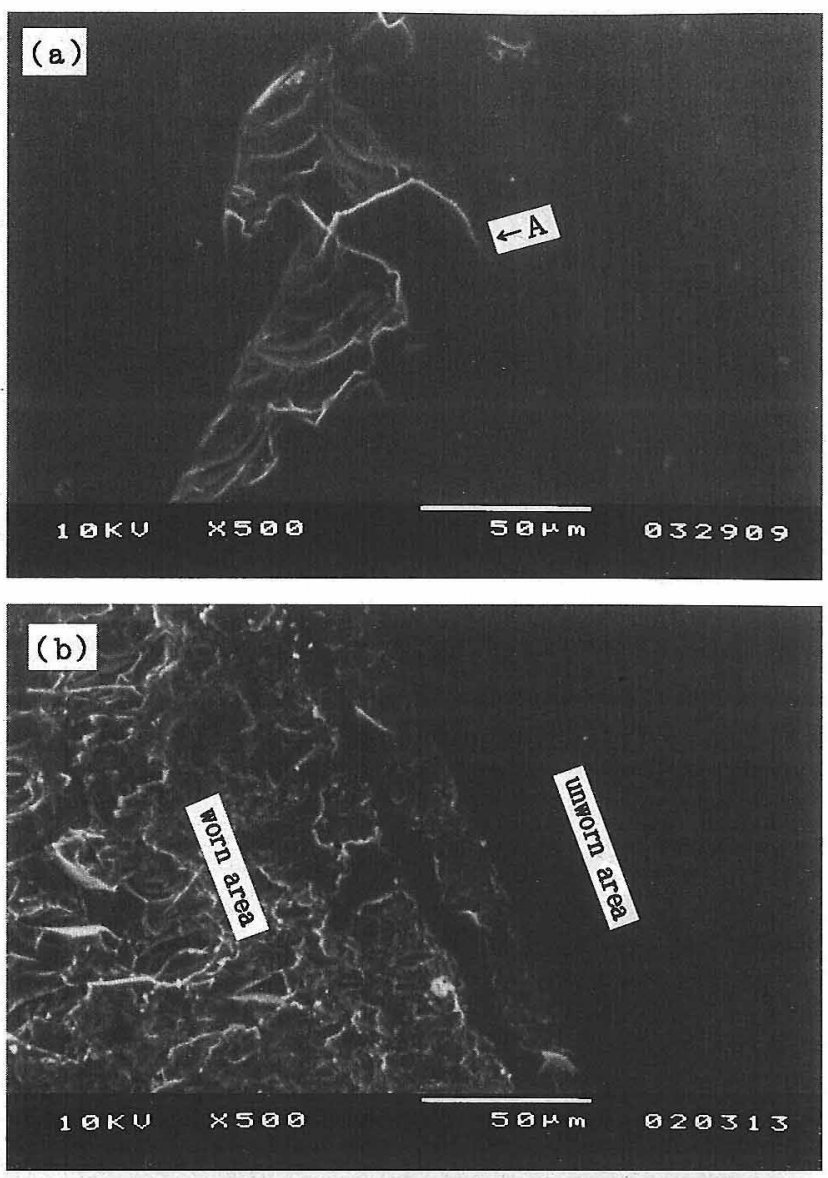

Fig. 11. Morphology of the worn track in GC samples at $0.1 \mathrm{~m} / \mathrm{s}$ and $9.8 \mathrm{~N}$, (a) slid against alumina, (b) slid against steel. Arrow " $\mathrm{A}$ " indicates a surface layer, which was coming off the surface.

(Fig. 12(b)). A roughly worn surface, however, was obtained in CD20 slid against steel. Its morphology was similar to the worn GC surface slid against steel, although the degree of roughness of CD20 was smaller than that of GC. This may indicate that delamination is also one of the main friction and wear processes of $\mathrm{CD} / \mathrm{GC}$ composites. The morphological observations may also indicate that the degree of delamination of $\mathrm{CD} / \mathrm{GC}$ composites (CD20) was smaller than that of GC.

\section{Conclusions}

The friction properties of cluster diamond/glassy carbon (CD/GC) composites and graphite cluster diamond/glassy carbon $(\mathrm{GCD} / \mathrm{GC})$ composites were studied to estimate their potential as self-lubricating materials in various environments. The friction tests were conducted by pairing the composites with three samples (i.e., steel, alumina and tungsten carbide) under conditions of a variety of sliding velocities, normal loads and three friciton environments (i.e., ambient air, low viscosity mineral oil and distilled water). On the basis of these results, we conclude the following:

(1) $\mathrm{CD}, \mathrm{GCD}$ and graphite particles were effective at improving the friction properties of GC. In particular, CD/ GC composites had the lowest friction coefficient in the group of GC matrix composites under the conditions applied in the test.

(2) When $\mathrm{CD} / \mathrm{GC}$ composites were slid against steel, a much lower friction coefficient $(<0.1)$ than that against alumina was observed. 

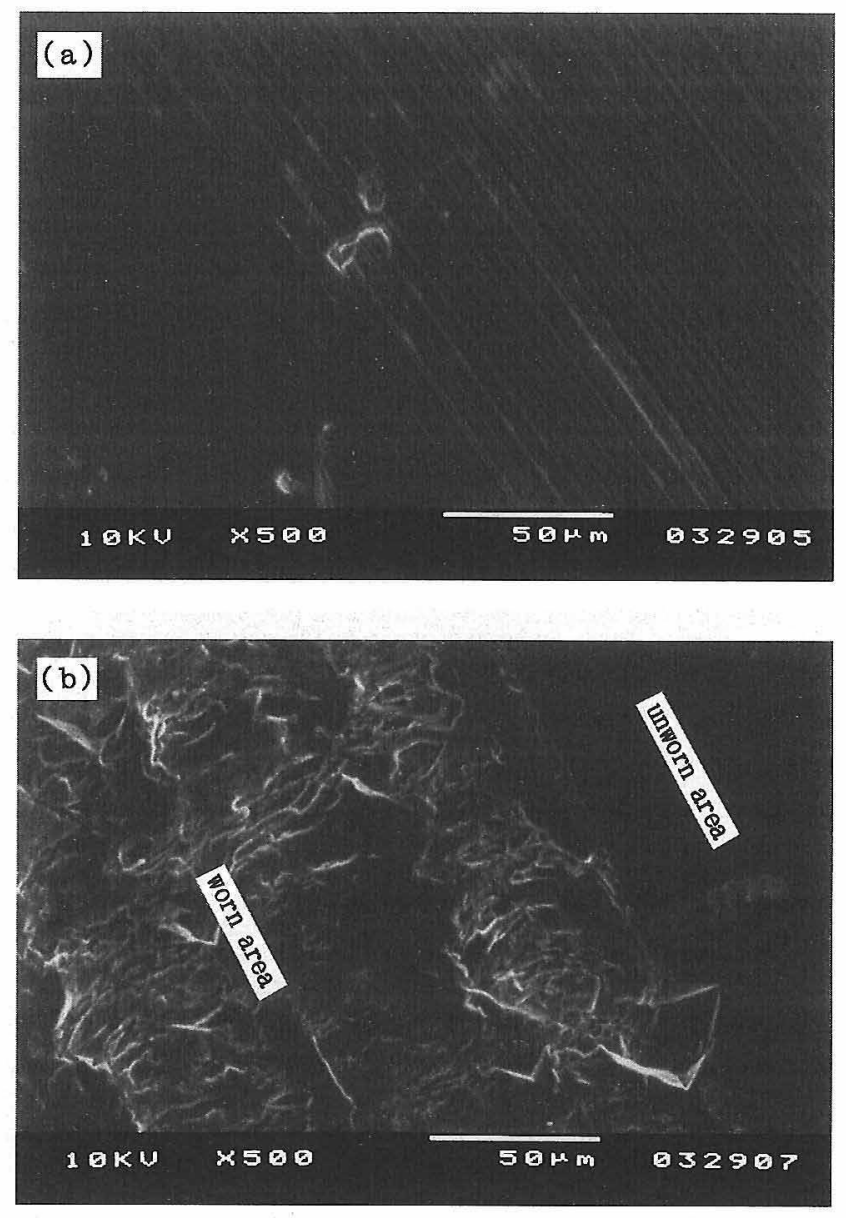

Fig. 12. Morphology of the worn track of CD20 samples at $0.1 \mathrm{~m} / \mathrm{s}$ and $9.8 \mathrm{~N}$, (a) slid against alumina, (b) slid against steel.
(3) The friction coefficient of $\mathrm{CD} / \mathrm{GC}$ composites and $\mathrm{GCD} / \mathrm{GC}$ composites tended to decrease as the normal load decreased. Under low sliding velocity and low loads, this tendency was clear, and the friction coefficient decreased as the CD contents increased.

(4) The friction properties of $\mathrm{CD} / \mathrm{GC}$ composites and $\mathrm{GCD} / \mathrm{GC}$ composites were not greatly influenced by the difference in friction environments of ambient air, low viscosity mineral oil and distilled water.

(5) These results indicate that $\mathrm{CD} / \mathrm{GC}$ composites have great potential for use as self-lubricating materials.

Acknowledgements The authors wish to express their thanks to Mr. Y. Suda and Mr. Y. Yamamoto of Mitsubishi Pencil Co., Ltd., for preparing the composite samples.

\section{References}

1) "Friction, Wear, Lubrication," Vol. 1, Ed. by I. V. Kragelsky and V. V. Alisin, Pergamon Press, Oxford, New York (1981) pp. 354-57.

2) T. Noda, M. Inagaki and S. Yamada, J. Non-Cryst. Solids, 1, 285-302 (1969).

3) L. Rapoport, L. Levin, I. Lapsker, A. Hoffman and H. Geller, Surf. Coat. Technol., 92, 110-19 (1997).

4) M. Hokao, S. Hironaka, Y. Suda and Y. Yamamoto, Wear, 237, 54-62 (2000).

5) T. Sano, Y. Murakoshi, H. Takagi, T. Homma, H. Takeishi and M. Mayuzumi, Mater. Trans., JIM, 37, 1132-37 (1996).

6) Q. Ouyang and K. Okada, Appl. Surf. Sci., 78, 309-13 (1994).

7) M. Yoshikawa, Y. Mori, H. Obata, M. Maegawa, G. Katagiri, H. Ishida and A. Ishitani, Appl. Phys. Lett., 67, 694-96 (1995).

8) H. Czichos, "Tribology," Elsevier, Amsterdam, Oxford, New York (1978) pp. 105-12.

9) E. Fitzer. W. Schaefer and S. Yamada, Carbon, 7, 643-48 (1969).

10) W. S. Rothwell, J. Appl. Phys., 39, 1840-45 (1968). 